\title{
OS ESCRITORES DA AMAZÔNIA DO SÉCULO XIX PARA ALÉM DAS HISTÓRIAS LITERÁRIAS
}

\section{NINETEENTH CENTURY AMAZON WRITERS: BEYOND LITERARY HISTORY}

\author{
Germana Maria Araújo Sales ${ }^{1}$ \\ Alan Victor Flor da Silva ${ }^{2}$
}

\begin{abstract}
RESUMO: Como podemos complementar a história literária vigente? Inúmeros trabalhos, ao longo dos anos, propõem uma leitura complementar ao que está disposto na História da literatura. Dessa forma, este artigo tem como objetivo apresentar as antologias literárias amazônicas como contribuição para a história da literatura brasileira a fim de recuperar autores de prosa de ficção da Amazônia do século XIX presentes nessas antologias do Oitocentos.
\end{abstract}

PALAVRAS-CHAVE: História da literatura brasileira. Antologias. Escritores da Amazônia do século XIX.

\begin{abstract}
How can we supplement our existing literary history? Numerous studies over the years have suggested a complementary reading to that which is provided in literary history. Likewise, this article aims to contribute to Brazilian literary history by presenting anthologies of Amazonian literature as a as a way of recovering the regional nineteenth century prose fiction writers presented in their pages.
\end{abstract}

KEYWORDS: History of the Brazilian literature. Anthologies. Amazon writers of the nineteenth century.

\footnotetext{
${ }^{1}$ Doutora em Teoria e História Literária (2003) pela Universidade Estadual de Campinas. Mestre em Teoria e História Literária (1997) pela Universidade Federal do Pará. Graduada em Letras (1989) Universidade Estadual do Ceará. Professora Associada da Faculdade de Letras, do Instituto de Letras e Comunicação (ILC) da Universidade do Federal do Pará. Belém, Pará, Brasil. E-mail: gmaa.sales@gmail.com

${ }^{2}$ Doutorando em Letras pela Universidade Federal do Pará. Mestre em Letras - Linguística e Teoria Literária (2014) pela Universidade Federal do Pará. Graduado em Letras - Língua Portuguesa pela Universidade Federal do Pará. Belém, Pará, Brasil. E-mail: alan.flor@hotmail.com
} 


\section{CONSIDERAÇÕES INICIAIS}

Todos já conhecem como a história literária brasileira foi construída ao longo dos séculos e acompanham o amplo debate que questiona a proposta de sua formatação. Carlos Alexandre Baumgarten (2014), por exemplo, avalia que os manuais dessa natureza transmitem uma falsa ideia da totalidade da literatura brasileira, quando deixam diversos autores e obras à margem e, por essa razão, diferentes formas de publicação - antologias e histórias literárias estaduais apresentam uma tentativa de complementar as lacunas existentes nos compêndios de história da nossa literatura.

A cena revelada pelas histórias literárias determina um número inexpressivo de autores da Amazônia de prosa de ficção, sobretudo em relação ao século XIX. Os únicos representantes desse período que encontramos nesses manuais são os paraenses Inglês de Sousa, Marques de Carvalho e José Veríssimo. ${ }^{3}$ No entanto, considerando que a Amazônia, durante o século XIX, era

\footnotetext{
${ }^{3}$ Para analisarmos a presença e a ausência de escritores da Amazônia do século XIX, selecionamos as seguintes histórias literárias: História da literatura brasileira, de José Veríssimo; Pequena história da literatura brasileira, de Ronald de Carvalho; História da literatura brasileira, de Nelson Werneck Sodré; História da literatura brasileira, de Lúcia Miguel Pereira; História da literatura brasileira, de Antônio Soares Amora; A literatura no Brasil, organizada por Afrânio Coutinho; Presença da literatura brasileira, de Antonio Candido
} 
um centro político-econômico, em razão da comercialização do látex, e Belém e Manaus constituíam as metrópoles da borracha, marcadas pela intensa modernização, não podemos deixar de desconfiar desse número irrisório de escritores representados nas histórias literárias.

Ao percebermos essa lacuna, recorremos às antologias organizadas a partir de critérios regionais, obras que representam claramente um objetivo e um intento historiográficos, visto que a finalidade é reverter a situação da produção literária amazônica no cenário nacional. Para este trabalho, selecionamos cinco antologias cujo discurso é favorável à literatura produzida na região: a Antologia amazônica, de José Eustáquio de Azevedo; a Lira amazônica, de Anísio Mello; a Seleta literária do Amazonas, de José dos Santos Lins; a Antologia da cultura amazônica, de Carlos Rocque; a Introdução à literatura no Pará, de Clóvis Meira, José Ildone e Acyr Castro. Apresentá-las-emos agora em ordem cronológica.

\section{ANTOLOGIA AMAZÔNICA}

No ano de 1904 foi publicada a Antologia amazônica, organizada pelo poeta, jornalista, novelista, romancista e cronista paraense José Eustáquio de Azevedo (1867-1943). ${ }^{4}$ Essa obra de propaganda literária, segundo o próprio

\footnotetext{
e José Aderaldo Castello; História concisa da literatura brasileira, de Alfredo Bosi; Breve história da literatura brasileira, de José Guilherme Merquior; História da literatura brasileira, de Massaud Moisés; História crítica do romance brasileiro, de Temístocles Linhares; Breve história da literatura brasileira, de Érico Veríssimo; História da literatura brasileira, de Luciana Stegagno-Picchio; A literatura brasileira, de José Aderaldo Castello; História da literatura brasileira, de Carlos Nejar. Para selecioná-las, optamos pelos seguintes critérios: 1) os compêndios deveriam apresentar a proposta de narrar toda a história da literatura brasileira, desde as primeiras manifestações até o momento literário do ano do lançamento. Em razão desse critério, não consideramos, por exemplo, a Formação da literatura brasileira (1959), de Antonio Candido, visto que o autor, nessa obra em especial, dedicou-se apenas a um momento específico da nossa literatura nacional. 2) o conceito de literatura utilizado pelos autores, mesmo que estivesse apenas implícito no decorrer de algumas obras, necessitaria estar atrelado a um campo literário restrito, de tal modo que os gêneros abarcados, delimitados justamente a partir desse conceito, se limitassem apenas à poesia, à crônica, ao teatro, ao conto, à novela e ao romance. Desse modo, excluímos a História da literatura brasileira (1888), de Sílvio Romero, pois o autor utilizou um conceito de literatura associado ao campo cultural e, por essa razão, abrangeu um número considerável de gêneros. 3) esses manuais também precisariam ter sido escritos por autores que tivessem algum prestígio no cenário literário nacional, seja como professores com formação acadêmico-universitária, a exemplo de Alfredo Bosi e Massaud Moisés; seja como homens das letras, a exemplo de José Veríssimo e Nelson Werneck Sodré; seja como escritores representantes da literatura brasileira, a exemplo de Érico Veríssimo e Carlos Nejar.

${ }^{4}$ Durante o século XIX, a Antologia amazônica ainda obteve duas reedições: uma em 1918 e outra em 1970. O projeto dessa obra idealizava dois volumes: o primeiro dedicado exclusivamente aos poetas paraenses e o segundo, por sua vez, aos amazonenses. A antologia, contudo, se limitou apenas ao primeiro volume.
} 
autor, foi uma provocação a partir do livro Poetas brasileiros contemporâneos, organizado pelo escritor Alexandre José de Mello Moraes Filho (1844-1919) e publicado pela primeira vez em 1903. Conforme Eustáquio de Azevedo, o trabalho de Mello Moraes Filho é censurável, pois os poetas da Amazônia não foram em nenhum momento contemplados.

O ilustre escritor [Mello Moraes Filho] parece que desconhece os poetas da Amazônia, muitos dos quais de real merecimento e dignos de serem citados: não os menciona. Se a omissão foi por ignorância ela é censurável num escritor como o sr. Mello Moraes Filho, que tem procurado estudar e conhecer homens de letras de seus país, publicando antologias; se ela foi proposital, mais censurável se torna ainda, pois que revela da parte do investigador uma espécie de ojeriza pelos literatos do Norte que não vivem no Sul... (AZEVEDO, 1918, p. 13)

Eustáquio de Azevedo afirma que a ausência dos poetas amazônicos do trabalho de Mello Moraes Filho é uma falha dolorosa e uma dura injustiça, mesmo que não tenha sido consciente. Para o intelectual paraense, esse descaso com os literatos do Norte, no entanto, não se resume apenas ao livro do escritor baiano. Eustáquio de Azevedo ressente-se pelo fato de que os autores conterrâneos conhecem um por um todos os letrados do Sul, mas o inverso não ocorre, visto que os literatos da Amazônia, segundo Eustáquio, ocupam um lugar marginal no cenário nacional das letras, condição que não se justifica pela qualidade estético-literária das obras produzidas pelos escritores amazônicos, mas acontece apenas em função da localização geográfica. Para Eustáquio, para obter prestígio e se tornar nacionalmente conhecido, o escritor deveria residir na capital do Brasil do século XIX para alcançar a consagração. Nesse sentido, o antologista paraense dedicou-se a escrever a Antologia amazônica com intuito de mostrar que "nesta nesga de pátria onde o Equador escalda e o Amazonas rebrame, há uma plêiade de poetas, distintos e inspirados, digna de acatamento e veneração" (AZEVEDO, 1918, p. 13).

Mas quais eram os nomes que ilustraram as páginas da antologia criada por Eustáquio de Azevedo? Para eleger o elenco da obra, foram mencionados 66 poetas paraenses, incluindo desde os mais antigos - Bento de Figueiredo Tenreiro Aranha (1769-1811) e Felipe Alberto Patroni Martins Maciel Parente (17981866) - até os mais contemporâneos ao antologista, a exemplo de Vilhena Alves (1848-1912), Santa Helena Magno (1848-1882) e Natividade Lima (1871-1897). A partir das minibiografias contidas na obra de Eustáquio de Azevedo, verificamos que apenas cinco desses escritores publicaram prosa de ficção: Gustavo Adolfo (1849/1850-?), Juvenal Tavares (1850-1907), Teodorico Magno (1866-1885), Marques de Carvalho (1866-1910) e Acrísio Mota (1866-1907). 


\section{LIRA AMAZÔNICA}

No ano de 1965, mais de cinquenta anos após a publicação da antologia de Eustáquio de Azevedo, o público conhece a Lira amazônica, projeto idealizado por Anísio Mello para ser publicado em três volumes. O primeiro, único que chegou a ser impresso, foi dedicado aos poetas dos estados do Amazonas, do Acre, de Roraima e de Rondônia. O segundo, por sua vez, seria destinado aos poetas do Pará e do Amapá, enquanto o terceiro e último, enfim, seria consagrado aos cronistas da Amazônia.

Anísio Mello planejou ainda publicar uma nova edição definitiva do primeiro volume da antologia com o objetivo de complementar os dados disponíveis referentes aos poetas e inserir alguns nomes que mereciam ser incluídos. O plano do autor, infelizmente, não teve êxito e o público ficou sem as informações complementares.

Conforme Anísio Mello, a Lira amazônica foi idealizada com o intuito de reparar uma grande injustiça, visto que muito já se escreveu sobre a Amazônia, mas muito pouco ou quase nada sobre os seus poetas. O autor da antologia afirma, por exemplo, que os escritores que se dedicaram ao cultivo de versos na região, salvo apenas algumas raríssimas exceções, jamais foram incluídos em antologias poéticas nacionais. Para dar forma ao seu projeto, Anísio Mello elegeu para compor a Lira amazônica tanto os poetas que nasceram na Amazônia quanto aqueles que residiam na região.

Embora Anísio Mello tivesse como objetivo a divulgação dos poetas da região, verificamos uma apresentação econômica das biografias, com apenas a indicação em alguns casos da naturalidade desses escritores. Desse modo, as informações acerca dos literatos ficaram restritas somente à produção poética sem demais elementos capazes de indicar, por exemplo, a incursão dos autores à produção de prosa de ficção.

A antologia de Anísio Mello abrange exatamente um total de 90 poetas, 24 a mais do que na obra de Eustáquio de Azevedo, desde o mais antigo - Bento de Figueiredo Tenreiro Aranha - até os mais coetâneos ao autor. $\mathrm{O}$ autor amazonense, ao final da obra, ainda lista 40 escritores que seriam incluídos posteriormente na versão ampliada dessa mesma antologia.

Desse total de 90 poetas, apenas dois não se dedicaram somente ao cultivo de versos, mas também à escrita de prosa de ficção: o cearense José Quintino Cunha (1873-1943) e o amazonense Paulino de Almeida Brito (1858-1919), como consta nas pequenas biografias referentes a esses escritores.

\section{SELETA LITERÁRIA DO AMAZONAS}

Um ano após a publicação da Lira amazônica, foi lançada a Seleta literária do Amazonas (1966), sob os auspícios do Governo do estado do Amazonas, 
organizada por José dos Santos Lins. Ao contrário do que ocorreu nas duas antologias apresentadas até aqui, o prefácio e a introdução dessa obra não foram escritos pelo autor da seleta, mas por Artur César Ferreira Reis ${ }^{5}$ (1906-1993) e por Mário Ypiranga Monteiro ${ }^{6}$ (1909-2004), respectivamente.

Na Seleta literária do Amazonas, José dos Santos Lins, ao contrário de Eustáquio de Azevedo e Anísio Mello, não compilou apenas produções escritas em versos. Ainda que o título dessa antologia indique que se trata de uma seleta literária, José Lins reuniu nessa obra uma parte significativa da produção cultural amazonense, tanto em prosa quanto em verso, desde a poesia, o teatro, o romance e a crônica diária de imprensa - gêneros, hoje, considerados caracteristicamente literários - até o ensaio crítico, a história e a página de interpretação sociológica gêneros apreciados, atualmente, como pertencentes a outros campos do conhecimento. Nesse sentido, percebemos que o conceito de literatura do qual o autor se imbuiu para selecionar escritores e obras apresenta um sentido amplo, visto que os gêneros selecionados não se restringem apenas aos que são considerados, hoje, tipicamente literários.

Além de optar por escritores que tenham se aventurado pelos mais variados gêneros de texto, o antologista, embora tenha organizado uma seleta literária do Amazonas com autores predominantemente amazonenses, expandiu o corpus para aqueles que provieram de outros lugares do Brasil e se fixaram nessa região. Sobre a naturalidade dos autores presentes na seleta literária de José Lins, Mário Monteiro (1966), na introdução do livro, afirma que "o Amazonas deve dar aos seus o que é seu por natureza e por filiação indireta. Não seria justo eliminar duma seleta nomes que aqui radicados muito contribuíram para elevar a cultura" (MONTEIRO, 1966, p. 18).

No prefácio da seleta, Artur Reis (1966) defende que a presença do Amazonas no processo intelectual e cultural brasileiro não teria sido convenientemente reconhecida. Para justificar esse lugar marginal, o autor do prólogo afiança que a falta de uma divulgação minuciosa da contribuição amazonense nesse processo acarreta o desconhecimento aos estudiosos e, por conta disso, os escritores do Amazonas não contam como parte integrante no âmbito dessa discussão. Dessa forma, Artur Reis, governador do estado nessa época, assegura que o trabalho de José Lins merecia reconhecimento público, visto que se tornava necessário garantir às novas gerações a compreensão do que o Amazonas representa em todas as esferas, desde o passado até o presente. Nesse sentido, Artur Reis assevera que a Seleta literária do Amazonas, considerada uma obra útil e necessária, merecia ser financiada e lançada pelo Governo, pois, para o autor do prefácio, imprimi-la significava pôr fim à ignorância nos outros estados e

\footnotetext{
${ }^{5}$ Governador do estado do Amazonas no período de 1964 a 1967, indicado a esse cargo por Humberto de Alencar Castelo Branco (1897-1967), primeiro presidente do período do regime militar.

${ }^{6}$ Advogado, jornalista, professor e escritor amazonense reconhecido pela contribuição e dedicação ao estudo da história do Amazonas.
} 
mesmo no próprio Amazonas acerca da grande contribuição às letras oferecida através dos séculos por escritores amazonenses ou provenientes de outras regiões.

$\mathrm{Na}$ introdução da seleta, por sua vez, Mário Monteiro garante que a obra organizada por José Lins não representa ainda o vasto acervo literário que o Amazonas poderia exibir. Segundo o autor da introdução, as lacunas presentes na antologia devem-se à dificuldade de acesso a documentos e fontes importantes para a coleta de informações sobre escritores - nomes geralmente ignorados ou sequer suspeitados de três ou quatro gerações - e obras - muitas vezes esgotadas e consideradas hoje raridades bibliográficas. Nesse sentido, a produção literária amazonense do passado, conforme Mário Monteiro, é desconhecida das novas gerações e, por essa razão, os jovens convencem-se de que, em tempos idos, nada houve de representativo no campo literário no estado, a exemplo de criações originais e produções de valor incontestável. Contudo, era do conhecimento de Mário Monteiro que a obra de José Lins dos Santos não tinha como fim a produção de uma História da Literatura do Amazonas. Ainda de acordo com Mário Monteiro, elaborar uma história da literatura amazonense exigiria uma completa reconstituição do passado e, portanto, não seria possível realizar esse feito numa simples antologia. Sobre a antologia de José Lins, Mário Monteiro afirma que "esta é apenas uma seleção, realizada sem qualquer preocupação em profundidade, do material mais à mão [...]. Não está defeituosa por isso mesmo. E é bom que se firme isso [...]: o conteúdo deste livro não é o máximo, é apenas o necessário como auxiliar didático" (MONTEIRO, 1966, p. 17).

A seleta literária de José Lins elege 71 intelectuais. Desse total, apenas um único autor pode ser considerado, com certeza, prosador da Amazônia do século XIX. Já mencionado neste trabalho, Paulino de Brito está presente na obra de José Lins por ter escrito gramáticas, poemas e romances. Pela atuação como romancista, o escritor amazonense é destacado pelas obras Dolores e O homem das serenatas.

\section{ANTOLOGIA DA CULTURA AMAZÔNICA}

A Antologia da cultura amazônica, composta em nove volumes e organizada por Carlos Rocque, foi lançada em 1970. Essa obra, ao contrário da Antologia amazônica, de José Eustáquio de Azevedo, e da Lira amazônica, de Anísio Mello, não se dedicou apenas aos poetas, assim como também não se prendeu a uma circunscrição estadual, a exemplo do Amazonas ou do Pará. Como o próprio título sugere, a Antologia da cultura amazônica reúne biografias e escritos de aproximadamente 800 intelectuais que se propuseram a escrever sobre a região amazônica e que se aventuraram pelos mais diversificados gêneros de texto, como poesia, conto, romance, ensaios históricos, memórias, narrativas de viagens, estudos geográficos, folclore, crônica, crítica, oratória e teatro.

É interessante salientarmos, aliás, que Carlos Rocque organizou todos os volumes da antologia justamente a partir desses gêneros: os dois primeiros são 
dedicados à poesia; o terceiro ao conto e ao romance; o quarto aos ensaios históricos e às memórias; o quinto às narrativas de viagens e aos estudos geográficos; o sexto à antropologia e ao folclore; o sétimo à crônica e à crítica; o oitavo à oratória e ao teatro; e o nono e último à ciência em geral.

A obra teve como objetivo delinear um painel completo de toda a cultura amazônica desde os primórdios, pois nenhuma obra do mesmo gênero conseguiu atingir tamanho feito. Carlos Rocque reconhece, no prefácio do primeiro volume, as demais obras publicadas anteriormente, como a Antologia amazônica, de Eustáquio de Azevedo, e a Lira amazônica, de Anísio Mello, volumes dedicados apenas aos poetas. Rocque considera também que a obra de José dos Santos Lins, a Seleta literária do Amazonas, por sua vez, deixa de incluir muitos nomes, em razão da rigorosa seleção imposta pelo restrito limite de páginas delimitado para a edição.

Desse modo, Carlos Rocque defende que, à exceção da obra de José dos Santos Lins, a antologia de Eustáquio de Azevedo e a de Anísio Mello dedicaram-se apenas ao campo poético e, por conseguinte, não contemplaram o conto, o romance, o ensaio, a crítica, a crônica, o teatro, entre outros. Segundo o autor, jamais houve uma preocupação de elaborar um levantamento biobibliográfico tão acurado da cultura amazônica. Nesse sentido, a antologia de Carlos Rocque representa uma importantíssima obra de vulgarização da produção escrita sobre essa região. Segundo o antologista paraense, a falta de divulgação, distribuição e impressão das obras de escritores da Amazônia é justamente uma das razões que contribuem para o total desconhecimento em nível nacional do que já se escreveu sobre essa parte do Brasil.

Para selecionar os escritores que deveriam ser inseridos na antologia, Carlos Rocque estabeleceu dois critérios: 1) o autor não precisaria ter nascido na Amazônia, mas deveria ter vivido na região pelo menos uma parte de sua vida e, sobretudo, ter contribuído para a sua cultura; 2) o autor também não apareceria mais de uma vez: mesmo que fosse poeta, romancista, contista e cronista, por exemplo, seria incluído no campo cultural no qual mais contribuiu.

De acordo com essas categorias estabelecidas na antologia de Carlos Rocque, é interessante observarmos que 292 escritores antologiados se destacaram mais pelo cultivo de versos, enquanto apenas 32 se sobressaíram mais como contistas e 30 como romancistas. Esse fato nos leva a inferir que a produção literária sobre a Amazônia se enveredou mais pelos caminhos da poesia.

Entre os prosadores listados, a maior parte possui uma produção que se concentra no século XX. Além de Inglês de Sousa e Marques de Carvalho, os poucos representantes do século XIX, segundo Carlos Rocque, são Agostinho Vianna (?-1916), Barroso Rebello (1867-?), Paulo Maranhão (1872-1966), João Affonso do Nascimento (1855-1924), Lourenço da Silva Araújo Amazonas (1803-1864) e Rodolfo Teófilo (1853-1932). 


\section{INTRODUÇÃO À LITERATURA NO PARÁ}

Dois anos após a publicação da obra de Carlos Rocque, veio a lume a Introdução à literatura no Pará, obra dividida em oito volumes, escrita sob os auspícios da Academia Paraense de Letras (APL) e organizada por Clóvis Meira, José Ildone e Acyr Castro, membros da principal agremiação literária instituída no estado. O primeiro volume foi lançado no ano de 1990 e o oitavo e último, por sua vez, foi lançado em 1997.

A antologia foi inspirada pelos autores com os seguintes objetivos: 1) promover o levantamento de todos os escritores que nasceram ou viveram no estado do Pará desde a fundação de Belém em 1616; 2) complementar ou subsidiar trabalhos anteriores elaborados com a mesma pretensão, assim como a Antologia amazônica, de José Eustáquio de Azevedo, e a Antologia de cultura amazônica, de Carlos Rocque; 3) formar "um desfiar de rostos que formalizem o que vem a ser [...] a prosa e a poesia criadas paraensisticamente" (MEIRA, ILDONE, CASTRO, 1990, vol. 1, p. 6); 4) atrair a atenção de professores e alunos para a produção literária desenvolvida no estado.

Embora tenham como pretensão elaborar uma obra que delineie os percursos da atividade literária no Pará desde o século XVIII, Clóvis Meira, José Ildone e Acyr Castro compreendem que "inexiste uma literatura paraense, desde que o fenômeno literário é um fato universal e não localista, o regional sendo reflexo de todo um sequenciamento de generalidades que põem o nacional prioritariamente no centro da discussão" (MEIRA, ILDONE, CASTRO, 1990, vol. 1, p. 7). Por essa razão, os membros da Academia Paraense de Letras decidiram atribuir à antologia o título de Introdução à literatura no Pará, pois ressaltam, desse modo, que há uma produção literária no estado que, por sua vez, pertence à literatura brasileira.

Para realizar a coleta de dados acerca dos escritores que produziram no Pará, a pesquisa foi dividida entre os antologistas da seguinte forma: a Clóvis Meira coube a tarefa de compilar os autores que exerceram a atividade da escrita nos séculos XVI, XVII, XVIII e XIX, desde o poeta amazonense Bento Figueiredo Tenreiro Aranha. Os poetas e prosadores da primeira metade do século XX ficaram sob a responsabilidade de José Ildone, enquanto a Acyr Castro coube compilar os representantes da segunda metade do mesmo século.

$\mathrm{O}$ resultado da pesquisa realizada pelos antologistas foi a reunião de mais de 430 escritores. Na Introdução à literatura no Pará, os verbetes de todos esses intelectuais apresentam informações biobibliográficas e uma miniantologia de textos, como poemas, crônicas, contos, discursos, ensaios críticos, entre outros.

$\mathrm{Na}$ obra de Clóvis Meira, José Ildone e Acyr Castro, é possível encontrarmos não apenas os intelectuais naturais do Pará, como também os radicados no estado. É interessante também ressaltarmos que os organizadores não inseriram na obra em questão apenas ficcionistas e poetas, mas também intelectuais que se dedicaram, sobretudo, ao campo religioso, político e/ou acadêmico-científico. 
Muitos dos intelectuais aludidos na obra dos membros da Academia Paraense de Letras exerceram a atividade jornalística. No Brasil, sabemos que a imprensa periódica foi responsável pela divulgação da produção literária de muitos escritores no século XIX. Até mesmo autores que alcançaram posteriormente o estatuto canônico chegaram a publicar poemas, crônicas, contos e romances primeiramente nas páginas de jornais e revistas para depois editá-los em livro, a exemplo de Joaquim Manoel de Macedo, Teixeira e Sousa, José de Alencar, Manuel Antônio de Almeida, Visconde de Taunay, Machado de Assis, Raul Pompéia e Aluísio de Azevedo (Cf. NADAF, 2009).

Seguindo a mesma tendência que se arrolava no restante do Brasil, muitos escritores da Amazônia no século XIX também deixaram uma parte significativa de sua produção literária lançada em periódicos. De acordo com Clóvis Meira, José Ildone e Acyr Castro, Marques de Carvalho, por exemplo, não apenas publicou o que produziu em livro, como também atuou como colaborador de diversos jornais belenenses oitocentistas, sobretudo nA Província do Pará, no Diário de Belém e no Diário do Grão-Pará, nos quais divulgou vários trabalhos, tanto em verso quanto em prosa. Segundo os antologistas, Paulino de Brito, escritor e jornalista amazonense radicado em Belém, assim como Marques de Carvalho, publicou trabalhos em livros (romances, poemas e gramáticas) e ainda deixou muito do que escreveu esparso pelos jornais da época. Poeta e jornalista amapaense, Múcio Javrot, pseudônimo de Joaquim Francisco Mendonça Júnior, também "deixou nos jornais a maior parte do que produziu, muita coisa ainda inédita" (MEIRA, ILDONE, CASTRO, 1990, vol. 5, p. 256).

Conforme os organizadores da Introdução à literatura no Pará, alguns autores nunca chegaram a publicar trabalhos em livros. Seus escritos, tanto em prosa quanto em verso, foram divulgados apenas em páginas de jornais e revistas oitocentistas. Poeta e jornalista paraense, Antônio Marques de Carvalho (18671915), por exemplo, "não deixou livros publicados. Seus trabalhos encontram-se nas páginas dos jornais e revistas da época em que viveu. [...] esqueceu de colecionar o que produzia" (MEIRA, ILDONE, CASTRO, 1990, vol. 3, p. 69). Do mesmo modo, Frederico Rhossard (1868-1900), poeta e jornalista paraense, não reuniu seus versos em livros. Segundo Clóvis Meira, José Ildone e Acyr Castro, Rhossard é "hoje desconhecido das novas gerações paraenses, inclusive pela falta de um livro que desse corpo ao que produziu" (MEIRA, ILDONE, CASTRO, 1990, vol. 4, p. 272). O poeta militou na imprensa paraense da época como redator do Diário do Grão-Pará, Diário de Belém, A Arena e Comércio do Pará. Nesses jornais, publicou todos ou quase todos os poemas que escreveu.

Na Literatura Paraense, José Eustáquio de Azevedo (1990) enumera alguns fatos que contribuíram para relegar a produção literária paraense a lugar periférico no âmbito das letras no Brasil. O autor afirma que a publicação de livros na região amazônica era um prazer do qual poucos escritores poderiam desfrutar, pois muitos não possuíam recursos financeiros suficientes para divulgar os seus trabalhos literários nesse formato de suporte. Nas biografias da Introdução à literatura no Pará, por exemplo, é possível percebermos que nenhum prosador ou poeta sobreviveu da própria pena. Além da atividade da 
escrita, esses intelectuais muitas vezes também eram jornalistas, professores, advogados, médicos, políticos e funcionários públicos. Esse fato nos leva a crer que na região amazônica, assim como no restante de todo país, a produção poética ou ficcional não era lucrativa. O jornal, portanto, era o meio mais acessível para que os poetas e os prosadores da Amazônia do século XIX disponibilizassem os seus escritos, pois esse suporte, em relação ao livro, apresenta um custo de produção mais baixo e, consequentemente, oferece um preço mais atrativo aos olhos dos leitores.

Conforme Clóvis Meira, José Ildone e Acyr Castro, os ficcionistas, no entanto, são poucos e muitos ainda enveredaram também pela produção de versos, a exemplo de Marques de Carvalho, Paulino de Brito e Bruno Seabra. Além desses três escritores de prosa de ficção, os antologistas mencionam Eustáquio de Azevedo, Inglês de Sousa, Juvenal Tavares, José Veríssimo e Teodorico Magno.

Considerando que na Introdução à literatura no Pará, assim como na Antologia amazônica, de Eustáquio de Azevedo, na Lira amazônica, de Anísio Mello, na Seleta literária do Amazonas, de José dos Santos Lins, e na Antologia da cultura amazônica, de Carlos Rocque, é possível afirmarmos que há um número considerável de escritores de prosa de ficção na e da Amazônia do século XIX para além do que atestam os compêndios de história da literatura brasileira. Para os pesquisadores da atualidade, fica a incumbência de decifrar esses escaninhos que, apesar do esforço reconhecido dos autores aqui listados, não foi suficiente para recuperar todos os nomes que compõem a história literária da Amazônia.

\section{REFERÊNCIAS}

AMORA, Antônio Soares. História da literatura brasileira. 8. ed. São Paulo: Saraiva, 1973.

AZEVEDO, José Eustáquio de. Antologia amazônica: poetas paraenses. 3. ed. Belém: Conselho Estadual de Cultura, 1918.

Literatura paraense. 3. ed. Belém: Fundação Cultural do Pará Tancredo Neves; Secretaria de Estado da Cultura, 1990.

BAUMGARTEN, Carlos Alexandre. A renovação do discurso historiográfico brasileiro. In: ANTUNES, Benedito; FERREIRA, Sandra (Organizadores). 50 anos depois: estudos literários no Brasil contemporâneo. São Paulo: UNESP, 2014.

BOSI, Alfredo. História concisa da literatura brasileira. 43. ed. São Paulo: Cultrix, 2006. 
CANDIDO, Antonio. Formação da Literatura Brasileira: momentos decisivos (1750-1880). 11. ed. Rio de Janeiro: Ouro sobre Azul, 2007.

; CASTELLO, José Aderaldo. Presença da literatura brasileira: história e antologia. 13. ed. Rio de Janeiro: Bertrand Brasil, 2008. 2. vols.

CARVALHO, Ronald de. Pequena história da literatura brasileira. 13. ed. Belo Horizonte: Itatiaia; Brasília: INL, Fundação Nacional Pró-Memória, 1984.

CASTELLO, José Aderaldo. A literatura brasileira: origens e unidade (15001960). São Paulo: Editora da Universidade de São Paulo, 1999. 2. vols.

COUTINHO, Afrânio (Organizador). A literatura no Brasil. 7. ed. São Paulo: Global, 2004. 6. vols.

LINHARES, Temístocles. História crítica do romance brasileiro. Belo Horizonte: Itatiaia; São Paulo: Editora da Universidade de São Paulo, 1987.

LINS, José dos Santos. Seleta literária do Amazonas. Manaus: Governo do Estado do Amazonas, 1966.

MEIRA, Clóvis; ILDONE, José; CASTRO, Acyr (Organizadores). Introdução à literatura no Pará: antologia. Belém: CEJUP, 1990. 8. vols.

MELLO, Anísio. Lira amazônica: antologia. São Paulo: Correio do Norte, 1965.

MERCHIOR, José Guilherme. Breve história da literatura brasileira: De Anchieta a Euclides. 4. ed. São Paulo: Realizações, 2014.

MOISÉS, Massaud. História da literatura brasileira. São Paulo: Cultrix, 19851989. 5. vols.

MONTEIRO, Mário Ypiranga. Introdução. In: LINS, José dos Santos. Seleta literária do Amazonas. Manaus: Governo do Estado do Amazonas, 1966.

NADAF, Yasmin Jamil. O romance-folhetim francês no Brasil: um percurso histórico. Letras (UFSM), v. 39, p. 119-138, 2009.

NEJAR, Carlos. História da literatura brasileira: Da Carta de Caminha aos contemporâneos. São Paulo: Leya, 2011.

PEREIRA, Lúcia Miguel. História da literatura brasileira: Prosa de ficção (de 1870 a 1920). São Paulo: Editora da Universidade de São Paulo, 1988.

REIS, Artur César Ferreira. Prefácio. In: LINS, José dos Santos. Seleta literária do Amazonas. Manaus: Governo do Estado do Amazonas, 1966. 
ROCQUE, Carlos. Antologia da cultura amazônica. Belém: Amazônia Edições Culturais Ltda. (AMADA), 1970. 9. vols.

ROMERO, Sílvio. História da literatura brasileira. 7. ed. Rio de Janeiro: José Olympio; Brasília: INL, 1980. 5. vols.

SODRÉ, Nelson Werneck. História da imprensa no Brasil. 3. ed. São Paulo: Martins Fontes, 1983.

STEGAGNO-PICCHIO, Luciana. História da literatura brasileira. Trad. Pérola de Carvalho e Alice Kyoko. 2. ed. Rio de janeiro: Nova Aguilar, 2004.

VERÍSSIMO, Érico. Breve história da literatura brasileira. Trad. Maria da Glória Bordini. São Paulo: Globo, 1995.

VERÍSSIMO, José. História da Literatura Brasileira: de Bento Teixeira (1601) a Machado de Assis (1908). São Paulo: Letras \& Letras, 1998.

Recebido em 19/09/2017

Aceito em 21/12/2017 